\title{
Effect of Femtosecond Irradiation Laser on the Optical Properties of
}

\section{GaAs Solar Cell}

\author{
Ruifang Chen ${ }^{1, a}$, Zhiguo Shi ${ }^{1, b}$, Yunxia Ye ${ }^{1, c}$, Xue Qing ${ }^{1, d}$, Yinqun Hua ${ }^{1,2, e^{*}}$ \\ ${ }^{1}$ School of Mechanical Engineering, Jiangsu University, \\ Zhenjiang Jiangsu , 212013, China \\ ${ }^{2}$ Insistute for Advanced Materials, Jiangsu University, \\ Zhenjiang Jiangsu, 212013, China \\ acrf0504@yahoo.com.cn, bshizhiguo629@163.com.cn, cyeyunxia@ujs.edu.cn, \\ dalphaqing@ujs.edu.cn, ehuayq@ujs.edu.cn \\ * please mark the corresponding author with an asterisk
}

Keywords: Femtosecond laser; Solar cell; Damage threshold; TiO2/SiO2 film.

Abstract. The results of damage on the GaAs solar cells surface irradiated by femtosecond laser show that: the anti-reflective layer irradiated by laser is damaged when the laser energy is more than $1 \mathrm{uJ}$; and when the energy is increased to $5 \mathrm{uJ}$, the anti-reflective layer is completely damaged. The comparison between theoretical damage depth and the experimental results reveal that: similarity between the theoretical calculation and experimental results is high when the laser energy is less than $6 \mathrm{uJ}$. There is no obvious change of the reflectance after irradiated by $1 \mathrm{uJ}$ pulse energy which is about $8 \%$, but it is increased to $32 \%, 38 \%$ after the pulse energy is increased to the $2 \mathrm{uJ}$ and $3 \mathrm{uJ}$. The quantum efficiency are decreased to $13.71 \%, 55.78 \%, 83.01 \%$ at $500 \mathrm{~nm}$ and $3.94 \%, 35.52 \%$, $46.78 \%$ at $800 \mathrm{~nm}$ when the cells are irradiated at $1 \mu \mathrm{J}, 2 \mu \mathrm{J}, 3 \mu \mathrm{J}$.

\section{Introduction}

With the rapid development of space research, the protection technology of high efficiency solar cells are becoming more and more important. The damage of optical film materials and devices by laser irradiation is the interest of the domestic and foreign scholars [1-4]. Optical thin film has always been the shattered part in optical elements [5], Tumer studied on the mechanism of the damage of optical thin films by laser irradiation, but he found that damage process of thin film irradiated by laser is very complicated [6]. The process not only depends on the parameters of the laser, but also relates to the physical properties of the membrane structure and membrane material. The whole process involves changes in thermal, photo voltaic, material properties and the electric field in films. A lot of exploration and research have been carried out, which include analyzing the effects of laser parameters, film characteristics and plating process on damage and researching the theory and experiment [7]. Le Drogoff B finds that the plasma generated by ultra short pulses exhibits a faster thermalization in comparison with plasmas produced by ns laser pulses [8].

GaAs solar cells are mainly used in the space satellite energy for the advantages of high conversion efficiency and great performance in radiation resistant and temperature resistant. Currently, the research about the injury on the solar cell irradiated mainly concentrates on energy effect and irradiation damage under the irradiation of high-energy charged particle from space. Robert proposed the design principle of the anti-radiation structure of GaAs solar cells after studied 
the damage effect of GaAs solar cells irradiated by proton and high-energy electron [9]. J. C. Bourgoin established the parameters of the GaAs solar cells electric performance parameters by researching the degradation behavior of irradiated cells including short circuit current and open circuit voltage [10]. Experiments on the effect of GaAs solar cell surface damage by femtosecond laser irradiation is carried out in this paper because of the fewer research on the laser damage on GaAs solar. Besides, the effects on the characteristics of the anti-reflective layer of the solar cells, such as damage, reflectance and QE, are studied by measuring and analyzing the SEM images, reflectance in the range of 300-1100 $\mathrm{nm}$ and the spectral response to provide reference for the selection of laser weapon, laser parameter and enhance space protection.

\section{Experiment Procedure}

GaAs/Ge solar cells fabricated by metal organic chemical gas phase deposition (MOCVD) are used in the experiments. The cells is covered by a $\mathrm{TiO} 2$ / SiO2 anti-reflective film layer thickness of about 100-150 $\mathrm{nm}$ above the window layer which can reduce the optical reflectance and the efficiency can be reached $18.5 \sim 19.5 \%$. The size of cell is $2 \mathrm{~cm} \times 3 \mathrm{~cm}$, and the anti-reflective structure of solar cell is shown in Fig. 1.

The experimental setup is schematically illustrated in Fig. 2. A regenerative amplified Ti: Sapphire femtosecond laser system (Spectra-physics) with the pulse duration of $130 \mathrm{fs}$, the central wavelength of $800 \mathrm{~nm}$ and the repetition rate of $1 \mathrm{KHz}$ was applied to process the GaAs solar cell surfaces in our experiments. The pulse energy could be continuously varied by using the combination of a $\lambda / 2$ wave plate and a Glan-Taylor polarizer. Lens A and Lens B make up the shrink-beam system. In the fabrication, the laser beam position was controlled by the Galvo Scanning System (Scanlab hurry SCANII) commanded by a computer. The average power of the laser pulse is designed for $1 \mathrm{uJ} \sim 14 \mathrm{uJ}$ (energy density $=0.13 \mathrm{~J} / \mathrm{cm} 2 \sim 1.18 \mathrm{~J} / \mathrm{cm} 2$ ) which is measured by a power meter (Coherent, FM10). The laser beam is focused by a biconvex lens with $50 \mathrm{~mm}$ focal length, and the diameter of the focal spot is about $22 \mu \mathrm{m}$. Before the laser treatment, the GaAs sheets are cleaned with acetone to remove organic dopants on the surface. The experiments are conducted by scanning the laser focused spot across the cell surface in air environment while controlling the pulse energy. The surface damage morphology of the vaporization $\mathrm{TiO} 2 / \mathrm{SiO} 2$ film is observed by optical microscope.

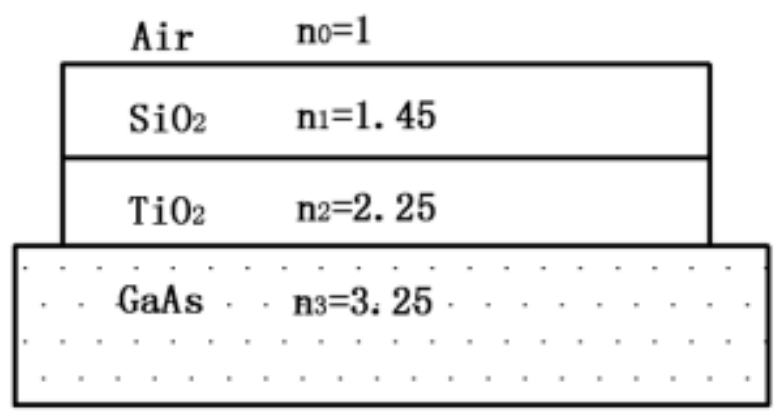

Fig. 1. Schematic of double-layer anti-reflective coatings. 


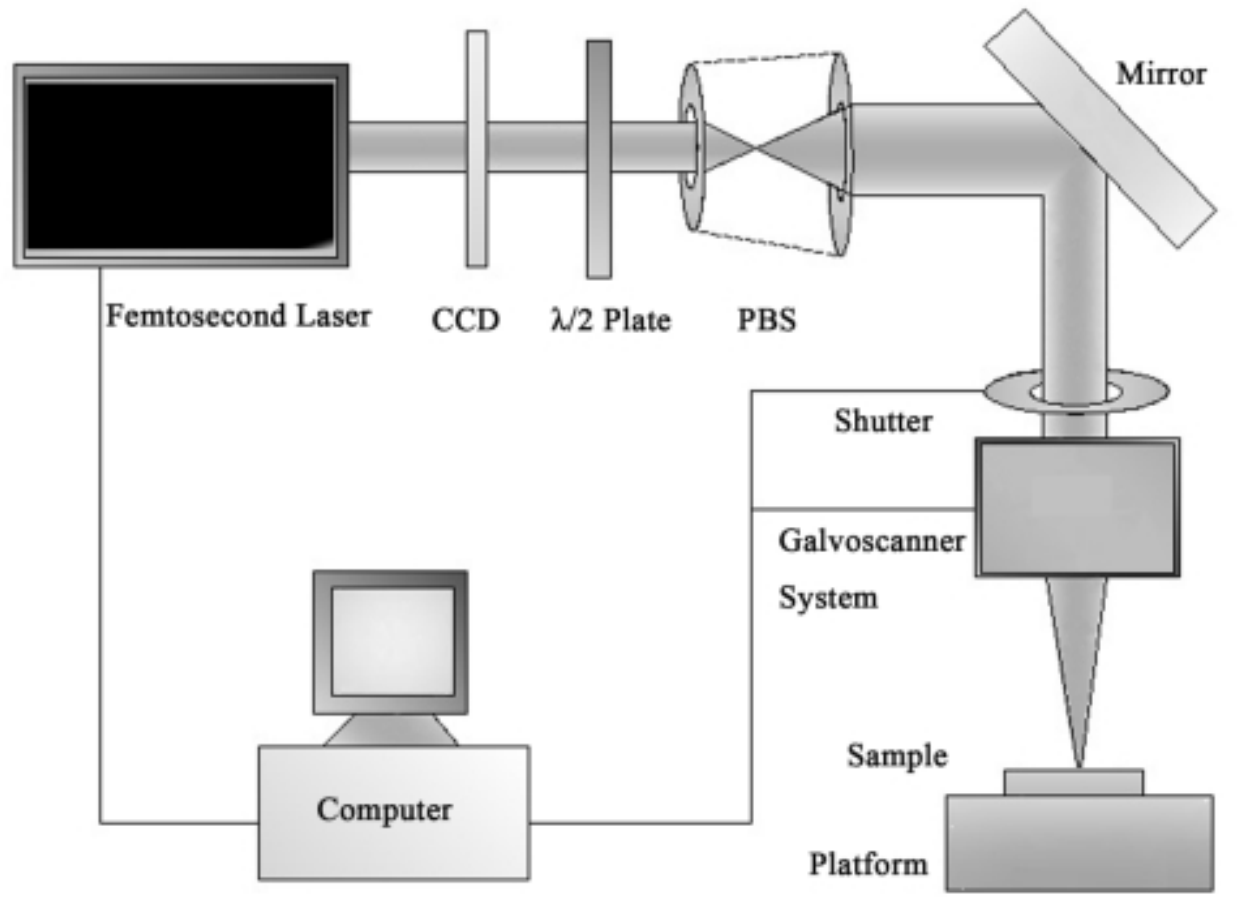

Fig. 2. Schematic illustration of the experimental setup.

\section{Results and discussion}

The analysis of damage on surface morphology by laser irradiation.

Fig. 3 represents damage morphology of the solar cells surface when the laser pulse energy is set as $2 \mathrm{uJ}, 3 \mathrm{uJ}, 4 \mathrm{uJ}, 5 \mathrm{uJ}$, respectively. The damage zone appears white. And the scanning speed is $22 \mathrm{~mm} / \mathrm{s}$. The size of damage area is smaller than the size of focus laser beam which is basically as shown in discrete area in Fig. 3(a). Fig. 3(b) reveals that the overlapped area appears but occupies a very small space. The overlap in the damage area is increased at a $4 \mathrm{uJ}$ energy and reached to $100 \%$ at the case of $5 \mathrm{uJ}$ eventually, which can be found in Fig. 3(c) and (d). Damaged area is increased and the condition of the light spot is changing from discrete to tangent until the the surface of the cell is damaged entirely.

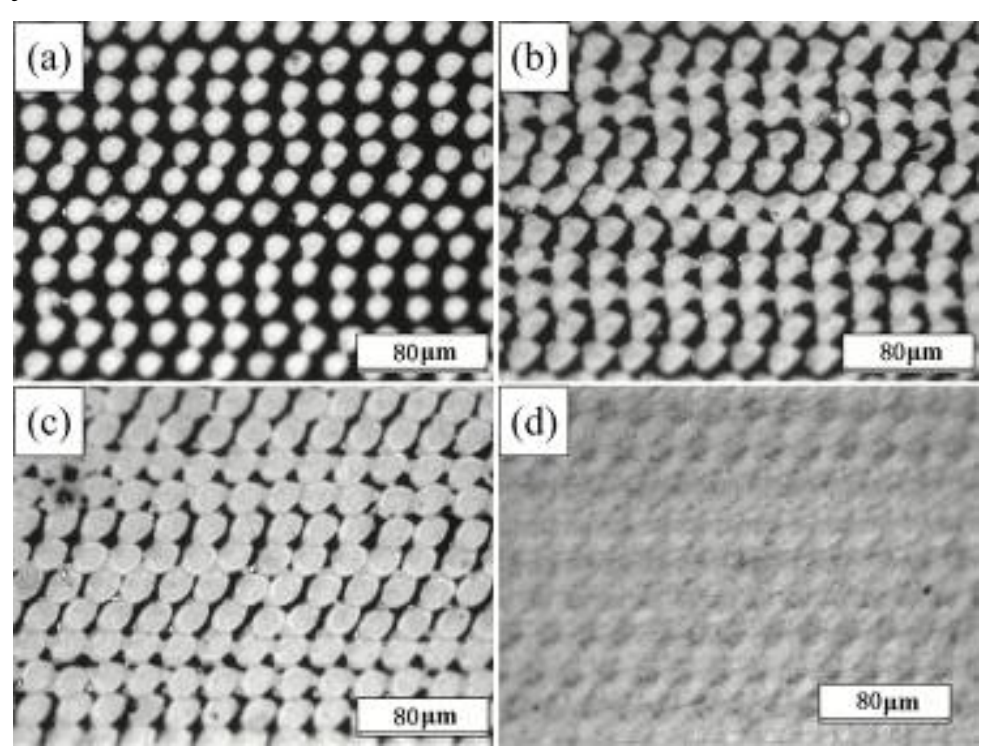

Fig. 3. SEM images of GaAs surface irradiated by femtosecond laser pulse: (a) $2 \mathrm{uJ}$, (b) $3 \mathrm{uJ}$, (c) 4 uJ, (d) $5 \mathrm{uJ}$. 


\section{The influence of laser energy on the damage depth of film surface.}

The study on the damage depth of the solar cell irradiated by femtosecond laser is continued to better express the damage morphology of solar cell. The structure of anti-reflective layer of GaAs solar cell is GaAs| (HL) |Air. The $\mathrm{H}$ and $\mathrm{L}$ represent the high and low refractive index materials of $\mathrm{TiO}_{2}$ and $\mathrm{SiO}_{2}$ respectively. The physical parameters of different materials is detailed shown in Tab. 1.

Tab. 1. The physical parameters of the coating material [9].

\begin{tabular}{ccccc}
\hline Material & $\begin{array}{c}\text { Vaporization } \\
\text { heat }[\mathrm{J} / \mathrm{kg}]\end{array}$ & $\begin{array}{c}\text { Density } \\
{\left[\mathrm{kg} / \mathrm{m}^{3}\right]}\end{array}$ & $\begin{array}{c}\text { Specific heat } \\
{[\mathrm{J} /(\mathrm{Kg} \cdot \mathrm{K})]}\end{array}$ & $\begin{array}{c}\text { Vaporization } \\
\text { temperature }[\mathrm{K}]\end{array}$ \\
\hline $\mathrm{L}\left(\mathrm{SiO}_{2}\right)$ & $1.383 \times 106$ & 2320 & 966 & 2503 \\
$\mathrm{H}\left(\mathrm{TiO}_{2}\right)$ & $3.762 \times 106$ & 3894 & 710 & 2943 \\
\hline
\end{tabular}

In order to analyze the relationship between the femtosecond laser energy and the thickness of the vaporized film, the hypothesis is as follows:

(1)The high temperature plasma not absorbing laser energy;

(2) The solar cell with an ideal smooth surface;

(3) The laser irradiation which damage the illuminated area but not affect the substance out of the area.

The vaporizing energy of the anti-reflective film by the energy conservation law is as follows in Eq. 1 [11]:

$$
A d u=\rho_{0} S\left(C T_{b}+L\right) d L^{\prime}
$$

Where $A$ is the coefficient of film absorption, $\rho_{0}$ is the density of films $\left(\mathrm{kg} / \mathrm{m}^{3}\right), S$ is the spot $\operatorname{size}\left(\mathrm{m}^{2}\right), C$ is the specific heat of the film $(\mathrm{J} / \mathrm{kg} \cdot \mathrm{K}), T_{b}$ is the vaporization temperature of different film material $(\mathrm{K}), L^{\prime}$ is the thickness of the anti-reflective layer and $L$ is the vaporization heat of film $(\mathrm{J} / \mathrm{kg})$.

The derivation result of Eq. 1 is as follow in Eq. 2:

$$
A \frac{d u}{d \tau}=\rho_{0} S\left(C T_{b}+L\right) \frac{d L^{\prime}}{d \tau}
$$

where $\frac{d u}{d \tau}$ is the laser power and $\frac{d L^{\prime}}{d \tau}$ is the vaporization velocity of film. Vaporization velocity of film can be got by Eq. 3,

$$
V=\frac{d L^{\prime}}{d \tau}=\frac{A q_{0}}{\rho_{0}\left(C T_{b}+L\right)}
$$


where $q_{0}=\frac{d_{u}}{d_{\tau}} / S$ is the laser power $\operatorname{density}\left(\mathrm{W} / \mathrm{m}^{2}\right)$ and $V$ is the vaporization velocity of film $(\mathrm{m} / \mathrm{s})$. The thickness of the vaporization layer is shown in Eq. 4:

$$
Z=\frac{A q_{0} \tau_{0}}{2 \rho_{0}\left(C T_{b}+L\right)}
$$

Where $\tau_{0}$ is the pulse duration. And the $q_{0}$ can be got from the Eq. 5:

$$
q_{0}=\frac{\alpha E}{\pi \tau_{0} r^{2}}
$$

where $E$ is the laser energy $(\mathrm{J}), r$ is the radius of focal spot and is the ratio heat energy to the internal energy of plasma. We can compute the thickness of the vaporization layer by insert Eq. 5 into Eq. 4.

The numerical values of the parameters are as follows: $C=838 \mathrm{~J} /(\mathrm{Kg} \cdot \mathrm{K}), L=3.762 \times 106 \mathrm{~J} / \mathrm{kg}$, $T_{b}=2723 \mathrm{~K}$ and $\rho_{0}=3110 \mathrm{~kg} / \mathrm{m}^{3}$, which are all the average from the values of $\mathrm{TiO}_{2}$ and $\mathrm{SiO}_{2}$ [12]. In addition, the pulse duration is $130 \mathrm{fs}$, the absorption coefficient of the laser on $\mathrm{TiO}_{2} / \mathrm{SiO}_{2}$ anti-reflective layer is $0.95, \alpha=0.15$ and the radius of the focal spot is $11 \mu \mathrm{m}$. Fig. 4 reveals the relation between the thickness of the anti-reflective layer and the laser pulse energy after the values into the Eq. 6.

$$
Z=\frac{\alpha A E}{2 \pi r^{2} \rho_{0}\left(C T_{b}+L\right)}
$$

The vaporization thickness of theoretical anti-reflective layer is $25 \mathrm{~nm}, 53 \mathrm{~nm}, 85 \mathrm{~nm}, 180 \mathrm{~nm}$, $200 \mathrm{~nm}, 350 \mathrm{~nm}$ and $400 \mathrm{~nm}$ when the femtosecond laser energy is $2 \mu \mathrm{J}, 4 \mu \mathrm{J}, 6 \mu \mathrm{J}, 8 \mu \mathrm{J}, 10 \mu \mathrm{J}, 12 \mu \mathrm{J}$ and $14 \mu \mathrm{J}$, respectively. Besides, the results of the experiment is $25 \mathrm{~nm}, 53 \mathrm{~nm}, 85 \mathrm{~nm}, 180 \mathrm{~nm}$, $200 \mathrm{~nm}, 350 \mathrm{~nm}$ and $400 \mathrm{~nm}$, respectively. From the fig. 4, it is found that the theoretical value are relatively accord with the experimental results when the laser energy is less than $8 \mu \mathrm{J}$, but the disparity between them is becoming great when the energy bigger than $8 \mu \mathrm{J}$, which is due to the materials in cell have been vaporized into another ones. The thickness of the $\mathrm{TiO}_{2} / \mathrm{SiO}_{2}$ anti-reflective layer is about $160 \mathrm{~nm}$, which is smaller than the vaporization thickness at the energy bigger than $8 \mu \mathrm{J}$. There is not a linear relationship between the actual laser damage thickness and laser energy. The reason that the actual damage thickness is significantly larger than the theoretical values calculated is not only because of the distribution of laser Gaussian beam, but also including the laser shock wave effect, the absorption coefficient of the laser on $\mathrm{TiO}_{2} / \mathrm{SiO}_{2}$ anti-reflective layer and errors in other parameters selection $[13,14]$. 


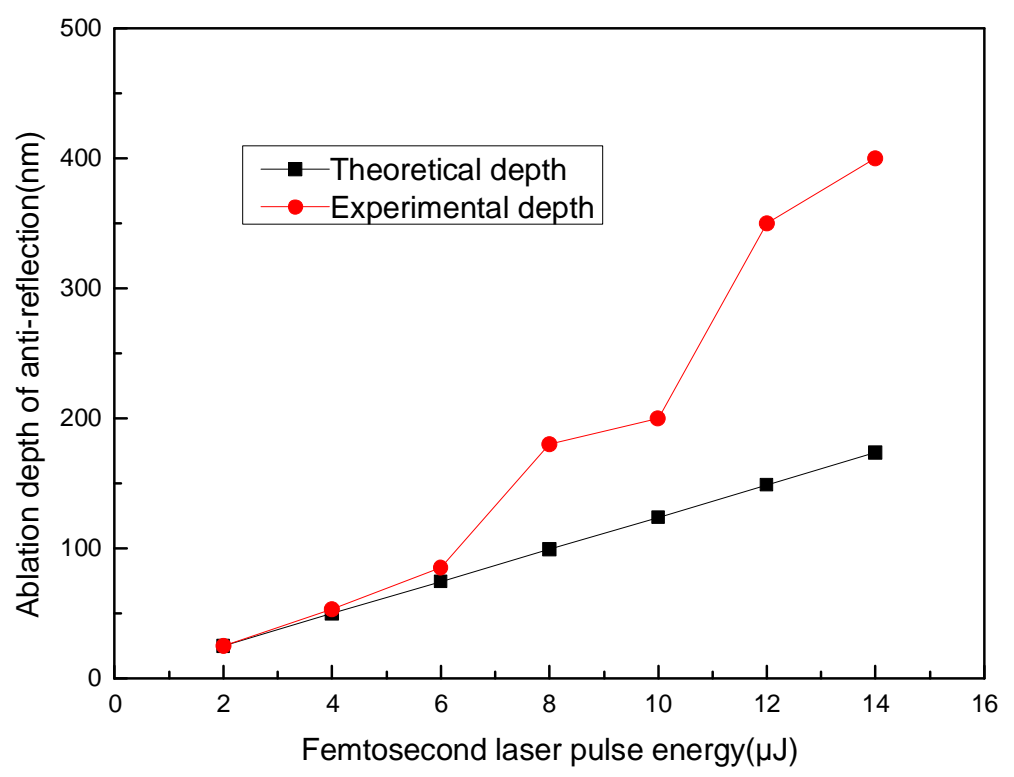

Fig. 4. The vaporization thickness of anti-reflective film as a function of laser energy.

\section{Anti-reflection analysis.}

The reflectance of the GaAs/Ge solar cell irradiated by different femtosecond laser energy density is as shown in fig. 5. It is found that the reflectance of solar cell is increased by with the increase of energy density. The increased reflectance can decrease the utilization of the incident light and resulting in the decrease of cell monochromatic incident photon-to-electron conversion efficiency(IPCE). The reflectance changes of the cell is not obvious when the energy density is 0.26 $\mathrm{J} / \mathrm{cm} 2(1 \mathrm{uJ})$ and the damage of the anti-reflective layer by laser irradiation is not serious, which reveals that the anti-reflective layer is not the main reason of $\eta$ decreasing $15 \%$. The reflectance of cell increases sharply at the wavelength of $400 \mathrm{~nm}$ and the average reflectance is about $15 \%$ in the range of $300-1100 \mathrm{~nm}$ when the energy density is $0.26 \mathrm{~J} / \mathrm{cm}^{2}(1 \mathrm{uJ})$, which indicates the anti-reflective layer is damaged seriously. The increased reflectance leads to the poor response of $\mathrm{I}-\mathrm{V}$ curve, and this result is consistent with the test results of the electrical properties above. The average reflectance increases to $38 \%$ in the whole band of 300-1100 nm when the energy density of the femtosecond laser increased to $0.79 \mathrm{~J} / \mathrm{cm}^{2}(3 \mathrm{uJ})$. Furthermore, the rate of increased reflectance is not obvious with the increase of laser energy density.

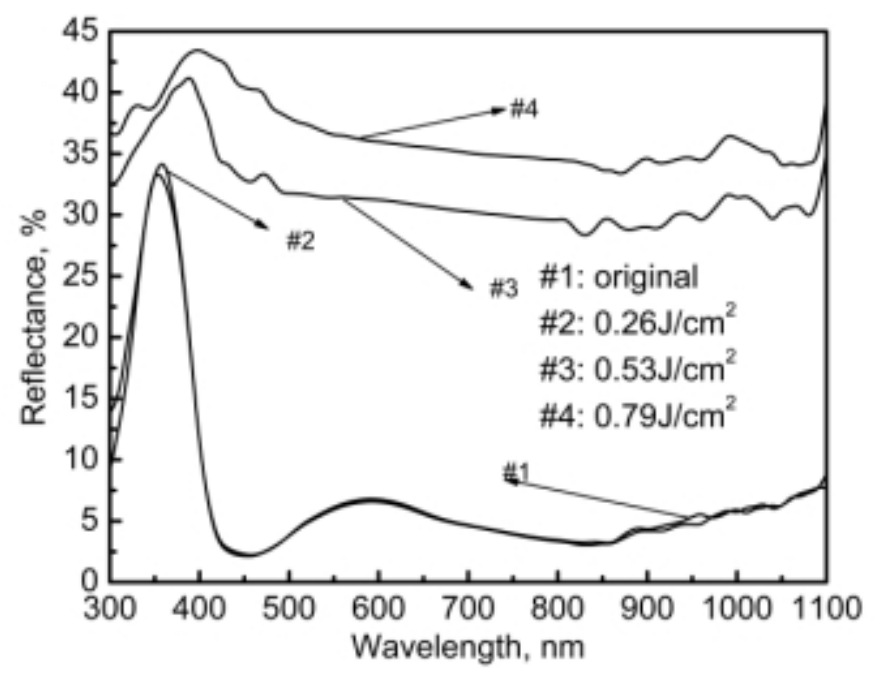

Fig.5 Variation of reflectance of GaAs/Ge solar cells before and after the femtosecond laser irradiation. 


\section{Spectral response analysis.}

Spectral response or quantum efficiency $(\mathrm{QE})$ refers to the capacity of solar cells inducing photo electron by a monochromatic light irradiation, also refers to ability of the photo electrons produced by photons incident on the solar cell. So QE and the intensity of the light source determine the current of the solar cell, and QE reflects the electrical properties of solar cells.

Fig. 6 represents the QE curve of the GaAs/Ge solar cell after irradiated by different laser density which is tangent with another spot. The decreased QE in the whole band when the energy density is $0.26 \mathrm{~J} / \mathrm{cm}^{2}(1 \mathrm{uJ})$, as well as no traces of surface damage was observed from the SEM images, which suggests true reason of the $\eta$ decreasing $15 \%$ is the decline of the QE, and the fundamental cause of the damage is laser producing defects on the cell surface and compounding the minority carrier in the interface. Besides, QE decrease obviously in the range of short and long wave when the energy density is $0.53 \mathrm{~J} / \mathrm{cm}^{2}$. The decrease of QE in the short wave means the damage in the window layer and the emission region of the solar cell, and the point defect increases the recombination of the carrier. The decrease of QE in the long wave reveals that damage is also caused in the base of cell, which shorten the lifetime of minority carriers or shorten the length of diffusion.

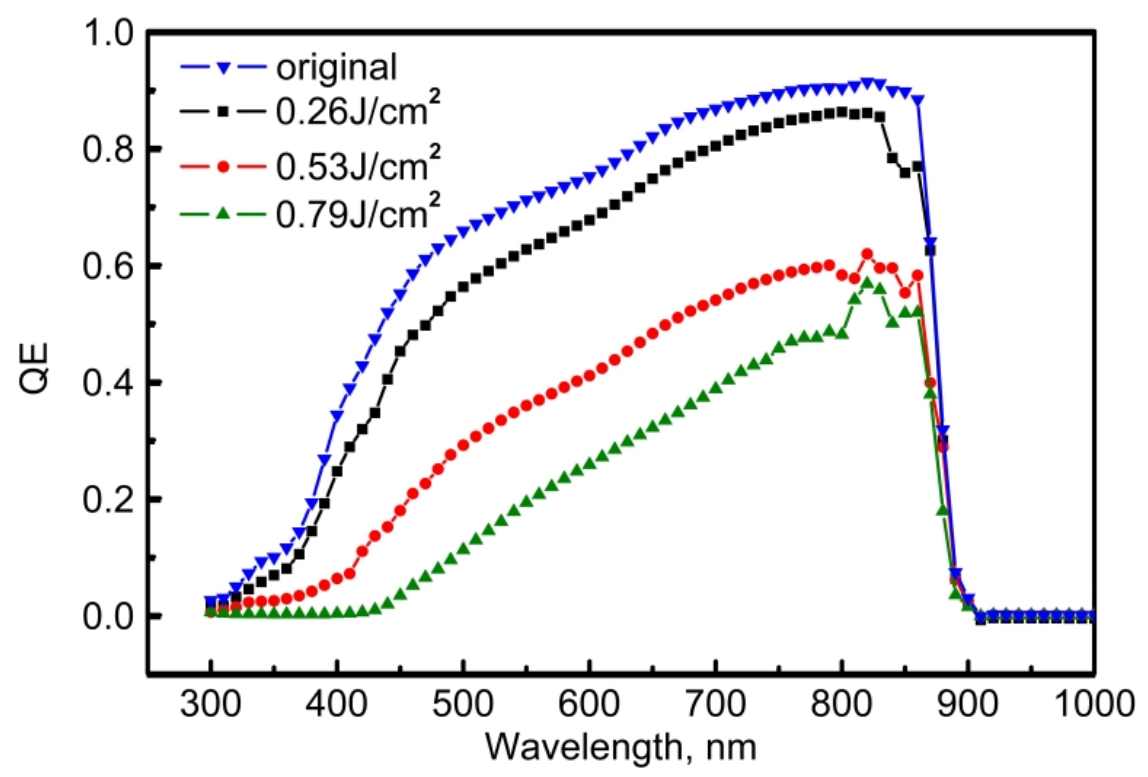

Fig. 6. Spectral response curve of GaAs/Ge solar cells before and after the femtosecond laser irradiation.

When the energy density of femtosecond laser is $0.26 \mathrm{~J} / \mathrm{cm}^{2}, 0.53 \mathrm{~J} / \mathrm{cm}^{2}, 0.79 \mathrm{~J} / \mathrm{cm}^{2}$, the QE decreases $13.71 \%, 55.78 \%$ and $83.01 \%$ at the wavelength of $500 \mathrm{~nm}$, as well as $3.94 \%, 35.52 \%$, $46.78 \%$ at the wavelength of $800 \mathrm{~nm}$, respectively. It can be concluded that the spectral response of the GaAs/Ge solar cell and the photo voltaic characteristic of the cell will be declined with the increase of the energy density of laser. The relation between the lifetime of minority carriers $(\tau)$, the length of diffusion $\left(L_{n}\right)$ and $\mathrm{I}_{\mathrm{sc}}$ is as follow in Eq. 7:

$$
I_{s c} \propto L_{n} \propto \tau^{1 / 2}
$$

As direct band gap semiconductor, GaAs can absorb most of the carriers which from the incident light in $\mathrm{p}$-GaAs layer after crossing anti-reflective layer and window layer. So, the capability determines the efficiency of the solar cell which transforms the carriers into photo current. The defects on the cell surface compound the minority carrier in the interface and also decline the QE of 
cell when the laser energy density is $0.26 \mathrm{~J} / \mathrm{cm}^{2}$. Finally, the electric performance of the GaAs/Ge solar cell is decreased. When the laser energy density is more than $0.53 \mathrm{~J} / \mathrm{cm}^{2}$, the shorten $\mathrm{L}_{\mathrm{n}}$ resulted from the introduced defects in the $\mathrm{p}-\mathrm{GaAs}$ region affects the generation of carriers diffusion and photo current directly. Besides, it will increase the recombination rate of the photo current on surface. All of these factors will make spectral response resulted in a decrease in the efficiency of cell. As the strength of the laser energy increased, the damage layer of cell is deeper, the defects in cell is more thick, the generation of photo current is harder, and the volt ampere characteristic of the cell is declining more.

\section{Conclusions}

1. In the process of femtosecond laser irradiation on GaAs solar cell, the damage of anti-reflective layer is becoming serious with the increase of energy, and the function of the anti-reflective layer will be no more when the laser energy reaches a certain value.

2. From the theoretical calculation of damage depth injured by the femtosecond laser irradiation, it can be found that the results of theoretical calculation and experiment are in good agreement.

3. The results of the measurement of the reflectance on the anti-reflective layer irradiated by the femtosecond laser indicate that the damage of anti-reflective layer is becoming serious with the increase of energy, which declines the function of it and increase the reflectance of the cell surface.

4. The response spectrum analysis shows that, with the increase of laser energy, the depth of the damaged cell layer and the defects in cell are increased. In addition, the photocurrent will be generated harder and the spectral response will decline constantly.

\section{References}

[1] Sun Chengwei, The effect of laser irradiation, National Defence Industry Press, Beijing, 2002.

[2] Liu Zhichao, Chen Songlin, et al, Characterization of $1064 \mathrm{~nm}$ nanosecond laser-induced damage on anti-reflective coating grown by atomic layer deposition, Optics Express. 20 (2012) 854-863.

[3] Rung S, Christiansen A. Hellmann R, Influence of film thickness on laser vaporization threshold of transparent conducting oxide thin-films, Applied Surface Science. 305 (2014) 347-351.

[4] Abreu Fernandes S, Schoeps B, et al, Femtosecond laser vaporization of ITO/ZnO for thin film solar cells, Physics Procedia. 41(2013) 802-809.

[5] Thomas I M, High laser damage threshold porous silica anti-reflective coatings, Appl. Opt. 25 (1986) 1481-1483.

[6] Turner. F, Ruby laser damage threshold in evaporated thin film and multi-layer coatings, NBS Spec Publ. 356 (1971) 12-119.

[7] Jasapara J, Nampoothiri. A. V. V, Rudolph W, Femtosecond laser pulse induced breakdown in dielectric thin films, PhysRev B. 63 (2001) 045117.

[8] Le Drogoff B, Margot J, M. Chaker, et al, Temporal characterization of femtosecond laser pulses induced plasma for spectrochemical analysis of aluminum alloys, Appl Phys. 56(2001) 987-1002.

[9] Robert. Y. Loo, G. Sanjiv Kamath, Sheng. S. Li, Radiation damage and annealing in GaAs solar cells, IEEE Transactions on Electron Devices. 37(1990) 485-497.

[10] J. C. Bourgoin, N. Angelis, Radiation-induced defects in solar cell materials, Solar Energy Materials and Solar Cells. 66 (2001) 467-477. 
[11] Yan Hong, Hua Yinqun, Chen Ruifang, Theoretic Study on the Thickness of coating in Laser Shocked Processing, Applied Laser. 26(2006) 10 12(In Chinese).

[12] Liu Guangqi, Ma Lianxiang, Liu Jie, Chemical Chemical Physical Data Handbook, Chemical Industry Press, Beijing, 2001. (In Chinese).

[13] Qiumei Bian, Xiaoming Yu, Baozhen Zhao, et al, Femtosecond laser vaporization of indium tin-oxide narrow grooves for thin film solar cells, Optics \& Laser Technology. 45 (2013) 395-401.

[14] Wang Wenting, Zhang Nan, Wang Ming-Weil, et al, Shock pressure in femtosecond laser vaporization of solid target, Acta Phys. Sin. 62 (2013) 170601(In Chinese) 